\title{
PERANCANGAN E-BAKUL PADA KELOMPOK WANITA TANI NGUDI REJEKI BERBASIS WEBSITE
}

\author{
Fajar Sarasati ${ }^{1)}$ Diah Pradiatiningtyas ${ }^{2)}$ Nani Purwati ${ }^{3)}$ \\ ${ }^{1}$ Program Studi Sistem Informasi, STMIK Nusa Mandiri \\ ${ }^{2}$ Program Studi Sistem Informasi, Universitas Bina Sarana Informatika \\ ${ }^{3}$ Program Studi Sistem Informasi Akuntansi, Universitas Bina Sarana Informatika \\ ${ }^{1}$ fajar.fss@nusamandiri.ac.id, ${ }^{2}$ diah.ddt@bsi.ac.id, ${ }^{3}$ nani.npi@bsi.ac.id
}

\begin{abstract}
Ngudi Rejeki Farmer Women Group is a feminine organization under the auspices of the food security agency and extension organizer (BKPPP) Bantul district as a forum for coaching and training its members to process and sell their own production of agricultural and livestock commodities, especially processed Moringa leaves, but the marketing strategy is less effective and efficient so that the market reach is not wide enough, order transactions are still done via WhatsApp or come directly to the store, so frequent errors in order recording and resellers need complete information about the product immediately, but the seller is not always ready to answer any questions from the reseller. Based on these problems the right media is needed to package processed products with the aim of attracting consumers and reducing the risk of errors in the transaction process. Authentic and objective data collection was obtained by the author through interview, observation and literature study methods for approximately 1 month and using software development method with SDLC waterfall (Waterfall) model according to Sukamto and Shalahuddin which consists of 5 stages, but the author only uses 2 stage namely analysis of software requirements and design. The results of data processing carried out by the author during the data collection process, the resulting E-BAKUL or E-Babakan Culinary web-based design is expected to be able to provide solutions to the problems experienced by KWT Ngudi Rejeki.
\end{abstract}

Keywords: Designing, E-BAKUL, Website

\begin{abstract}
Abstrak
Kelompok Wanita Tani Ngudi Rejeki merupakan suatu organisasi kewanitaan dibawah binaan badan ketahanan pangan dan pelaksana penyuluhan (BKPPP) kabupaten Bantul sebagai wadah pembinaan dan pelatihan anggotanya untuk mengolah dan menjual sendiri hasil produksi komoditas pertanian dan peternakan khususnya olahan daun kelor, namun strategi pemasaran yang dilakukan kurang efektif dan efisien sehingga menyebabkan jangkauan pasar kurang luas, transaksi pemesanan masih dilakukan via WhatsApp atau datang langsung ke toko, sehingga sering terjadi kesalahan pencatatan pesanan serta reseller membutuhkan informasi lengkap tentang produk dengan segera, namun penjual tidak selalu siap melayani setiap pertanyaan dari reseller. Berdasarkan permasalahan tersebut maka media yang tepat sangat diperlukan untuk mengemas produk olahan dengan tujuan untuk menarik konsumen serta mengurangi resiko kesalahan pada proses transaksi. Pengumpulan data yang otentik dan objektif diperoleh penulis melalui metode wawancara, observasi dan studi pustaka selama kurang lebih 1 bulan serta menggunakan metode pengembangan perangkat lunak dengan model SDLC air terjun (Waterfall) menurut Sukamto dan Shalahuddin yang terdiri dari 5 tahap, namun penulis hanya menggunakan 2 tahap yaitu analisis kebutuhan perangkat lunak dan desain. Hasil pengolahan data yang dilakukan penulis selama proses pengumpulan data, maka dihasilkan rancangan E-BAKUL atau E-Babakan Kuliner berbasis website yang diharapkan mampu memberikan solusi dari permasalahan yang dialami KWT Ngudi Rejeki.
\end{abstract}

Kata Kunci: Perancangan, E-BAKUL, Website 


\section{PENDAHULUAN}

Bantul merupakan salah satu kota di provinsi Daerah Istimewa Yogyakarta yang memiliki komoditas unggul di beberapa bidang khususnya di bidang pertanian dan peternakan. Namun komoditas sebanyak dan seunggul apapun jika tidak di imbangi dengan skill khusus dari masyarakatnya untuk mengolah, maka komoditas utama daerah bantul tidak akan berkembang dan menjadi produk khas daerah tersebut. Pemerintahan Jokowi-JK sendiri sedang gencar-gencarnya menjalankan program pembangunan Nawa Cita atau agenda prioritas kabinet kerja mengarahkan pembangunan pertanian ke depan untuk mewujudkan kedaulatan pangan, agar Indonesia dapat mengatur dan memenuhi kebutuhan pangan rakyatnya secara berdaulat [1]

Namun tidak sedikit masyarakat yang masih mengalami kesulitan dalam memasarkan produknya, menguasai pasar, menentukan standar produksi, dan pengemasan produk dikarenakan basic skill masyarakat desa sebagian besar bercocok tanam dan beternak, sehingga beberapa usaha milik masyarakat belum menetapkan target standar produksi pengadaan bahan baku, pemeliharaan alat, pengendalian terhadap mutu produk dan beberapa produk belum sesuai dengan target standar packing sebagai persyaratan teknis untuk kepentingan distribusi dan promosi produk seperti kemasan produk belum diberi label produk sehingga konsumen sulit dalam mengenali brand produk, informasi produk, petunjuk penggunaan, serta tanggal kadaluwarsa pada produk. Selain itu pemasaran produk masih dipasarkan dengan membuka toko atau warung makan dengan memanfaatkan rumah.

Kelompok Wanita Tani Ngudi Rejeki merupakan suatu organisasi dibawah binaan badan ketahanan pangan dan pelaksana penyuluhan (BKPPP) kabupaten Bantul yang terbentuk karena adanya gempa bumi pada tahun 2006, dimana para relawan membuat program perkumpulan ibu-ibu yang bertujuan untuk meningkatkan penghasilan para petani dengan mengolah hasil pertanian milik petani kecuali yang berbahan dasar tepung terigu. Strategi pemasaran yang dilakukan oleh sebagian produsen yang merupakan anggota KWT Ngudi Rejeki kurang efektif dan efisien mengakibatkan hasil penjualan belum sesuai target penjualan yang telah diharapkan. Permasalahan lainnya yang dilakukan anggotanya dari segi transaksi dimana pemesanan atau pembelian masih dilakukan via WhatsApp atau datang langsung ke toko, pencatatan pesanan, bukti nota pembelian, dan perhitungan transaksi juga masih dilakukan secara manual sehingga penjual sering melakukan kesalahan pada saat pencatatan pesanan dan perhitungan pembelian, kesalahan pada pemberian harga produk antara reseller dan pelanggan serta permasalahan dari segi reseller yaitu ketika reseller membutuhkan informasi secara lengkap dengan segera namun penjual tidak selalu siap melayani pertanyaan reseller.

Program Wisata Kuliner merupakan program yang mengangkat beragam makanan. Kegiatan dalam wisata kuliner, seperti: mencicipi makanan di restoran-restoran etnik, mengunjungi festival makanan, mencoba makanan pada saat melakukan perjalanan wisata bahkan memasak di rumah [2]. Sedangkan E-Commerce sendiri merupakan penjualan dan pembelian produk, informasi dan jasa yang dilakukan dengan memanfaatkan jaringan komputer, misalnya internet. Dengan E-Commerce perusahaan dapat menekan biaya yang harus dikeluarkan untuk keperluan informasi (iklan), selain dengan e commerce transaksi bias berlangsung dengan cepat dan biaya lebih efisien, sehingga dapat meningkatkan kemampuan perusahaan dalam bersaing [3].

Media yang tepat sangat diperlukan untuk mengemas aneka produk olahan hasil pertanian dan peternakan agar lebih menarik konsumen dan mengangkat produk yang belum berkembang serta memberi kemudahan bagi masyarakat yang kurang menguasai strategi penguasaan pasar dan masih mengalami kesulitan untuk memasarkan produknya. Dengan adanya sistem informasi juga akan mempermudah suatu perusahaan atau instansi didalam melakukan proses pengolahan data dengan pengambilan keputusan yang tepat bagi pihak manajemen [4].

Berdasarkan permasalahan tersebut maka penulis berusaha menerapkan program wisata kuliner dengan memanfaatkan perkembangan yang pesat dibidang teknologi informasi dan teknologi [5] yang diterapkan dalam bentuk ECommerce dengan merancang sistem informasi berbasis website E-Kuliner atau 
semacam E-Commerce wisata kuliner yang untuk mengemas aneka produk olahan hasil pertanian dan peternakan di kabupaten Bantul dengan konsep desa wisata kuliner Bantul dengan nama E-BAKUL atau E-Babakan Kuliner Bantul berbasis website.

\section{METODE PENELITIAN}

Metode penelitian merupakan tahap untuk membangun sistem aplikasi yang dibangun, dilakukan secara berurutan [6].

Metode penelitian dan teknik pengumpulan data yang digunakan untuk mendapatkan datadata yang otentik dan objektif dalam penyusunan laporan Tugas Akhir meliputi metode pengumpulan data dan metode pengembangan perangkat lunak berikut ini:

1. Metode Pengumpulan Data

a. Wawancara

Dengan mewawancarai Ibu Siti Haida Hutagaol selaku salah satu anggota Kelompok Wanita Tani (KWT) Ngudi Rejeki yang menjabat sebagai sekretaris dan juga merupakan owner Kelorida. Informasi yang diperoleh dengan teknik pengumpulan data ini meliputi: permasalahan pokok yang dialami KWT Ngudi Rejeki khususnya pada proses promosi, pemasaran produk, penjualan, pencatatan penjualan, pencatatan pesanan dan pencatatan bukti transaksi, hingga proses pengiriman barang, serta prosedur sistem berjalan pada proses pemsaran dan penjualan produk.

b. Observasi

Observasi ini dilakukan dengan mengamati proses kegiatan yang berlaku di tempat penelitian [6]. Pada teknik pengumpulan data dengan observasi dilakukan selama kurang lebih 1 bulan meliputi pengamatan proses promosi, proses penjualan, pencatatan penjualan pada buku hingga pencatatan bukti transaksi yang masih dilakukan secara manual sehingga sering terjadi kesalahan pada saat pencatatan dan perhitungan pembelian khususnya bagi penjual yang belum hafal harga produk, pencatatan pesanan produk terkadang tidak sesuai dengan jumlah produk, dan juga sering terjadi kesalahan pemberian harga produk antara reseller dan pembeli.

2. Metode Pengembangan Perangkat Lunak Model SDLC air terjun (Waterfall) atau sering juga disebut model sekuensial linier (sequential linier) atau alur hidup klasik (classic life cycle). Model air terjun menyediakan pendekatan alur hidup perangkat lunak secara sekuensial atau terurut dimulai dari analisis, desain, pengodean, pengujian, dan tahap pendukung (support) atau pemeliharaan (maintenance) [7].

Berikut model pengembangan sistem dengan waterfall [8].

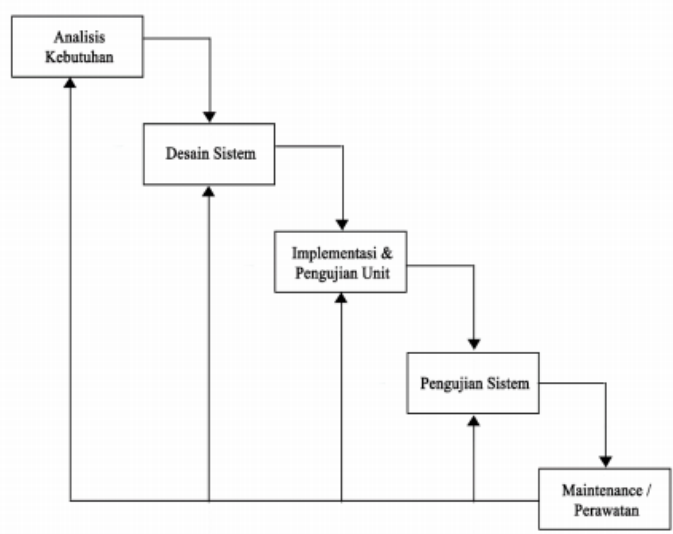

Sumber: [Rachman, dkk :2017]

Gambar 1. Metode Waterfall

Keterangan gambar:

1. Analisa kebutuhan

Proses pengumpulan kebutuhan dilakukan secara intensif untuk mespesifikasikan kebutuhan perangkat lunak agar dapat dipahami perangkat lunak seperti apa yang dibutuhkan oleh user. Spesifikasi kebutuhan perangkat lunak pada tahap ini perlu untuk didokumentasikan.

2. Desain sistem

Desain Sistem adalah proses multilangkah yang fokus pada desain pembuatan program perangkat lunak termasuk struktur data, arsitektur perangkat lunak, representasi antarmuka, dan prosedur pengodean.

3. Implementasi \& Pengujian Unit

Desain harus ditranslasikan ke dalam program perangkat lunak. Hasil dari tahap ini adalah program komputer 
sesuai dengan desain yang telah dibuat pada tahap desain.

4. Pengujian Sistem

Tahapan ini bisa dikatakan final dalam pembuatan sebuah sistem. Pengujian fokus pada perangkat lunak secara dari segi lojik dan fungsional dan memastikan bahwa semua bagian sudah diuji. Hal ini dilakukan untuk meminimalisir kesalahan (error) dan memastikan keluaran yang dihasilkan sesuai dengan yang diinginkan.

5. Maintenance/Perawatan

Perangkat lunak yang susah disampaikan kepada pelanggan pasti akan mengalami perubahan. Perubahan tersebut bisa karena mengalami kesalahan karena perangkat lunak harus menyesuaikan dengan lingkungan (periperal atau system operasi baru) baru, atau karena pelanggan membutuhkan perkembangan fungsional

Model SDLC air terjun (waterfall) yang terdiri dari 5 tahapan, dan pada penelitian ini penulis hanya mengguanakan 2 tahap antara lain: [7]

a. Analisis kebutuhan perangkat lunak

Kebutuhan dalam merancang sistem E-

BAKUL berbasis website meliputi:

Kebutuhan fungsional diantaranya pada menu admin sistem dapat melakukan penginputan dan penghapusan data produsen, reseller, dan pelanggan, serta menampilkan daftar penjualan.

Pada menu produsen sistem dapat melakukan pengubahan data diri, upload gambar dan video tentang produk, penginputan data stok produk, informasi manfaat produk, harga dan spesifikasi produk, serta melihat daftar penjualan produk.

Pada menu reseller sistem dapat melakukan pengubahan data diri, sistem menyediakan fitur download gambar atau video, menyalin informasi, harga dan spesifikasi produk, pemesanan produk hingga pembayaran, serta mencetak bukti pesanan. Pada menu pelanggan sistem dapat memesan produk hingga pembayaran, serta mencetak bukti pesanan.
Kebutuhan Non-fungsional meliputi sistem dapat dijalankan oleh beberapa software web browser diantaranya Google Chrome, Mozilla Firefox, dan Internet Explorer. Sistem memiliki tampilan yang mudah dipahami oleh admin, produsen, reseller, maupun pelanggan.

b. Desain (Perancangan)

Pada tahap ini penulis melakukan proses desain perancangan E-BAKUL berbasis website diantaranya perancangan struktur data, arsitektur perangkat lunak, dan representasi antarmuka. Pada tahap ini dirancang pula halaman website khusus untuk admin, produsen, reseller, dan pelanggan dalam bentuk mook up, serta merancang halaman website daftar produk, halaman informasi, gambar dan video produk, dan halaman daftar menjadi reseller atau pelanggan, cetak bukti pesanan, konfirmasi pesanan, halaman informasi status pengiriman serta halaman kirim komentar dan testimoni dan antarmuka lainnya.

c. Tahap Pengujian

Pada tahap pengujian sistem yang berjalan akan dilakukan pengujian dengan menggunakan Black box testing. Dimana Black box testing berfokus pada spesifikasi fungsional dari perangkat lunak. Tester dapat mendefinisikan kumpulan kondisi input dan melakukan pengetesan pada spesifikasi fungsional program [9].

Beberapa diagram Unified Modelling Language (UML) sebagai alat bantu dalam menganalisa sistem untuk mendeskripsikan proses bisnis sistem yang sedang berjalan serta mendeskripsikan konsep sistem baru yang akan dikembangkan dimana sistem baru tersebut tentunya dapat memberikan solusisolusi dari permasalahan yang ada serta memenuhi kebutuhan sistem, terdiri dari: [4]
a. Activity Diagram
b. Use Case Diagram
c. Use Case Description 


\section{HASIL DAN PEMBAHASAN}

A. Sistem Manual

\section{Prosedur Sistem Berjalan}

a. Prosedur Pembelian

Pada proses pembelian produk yang dilakukan oleh pelanggan maupun reseller dibagi menjadi dua yaitu pembelian dengan langsung datang ke toko atau dengan pemesanan melalui media WhatsApp.

b. Proses Pembayaran

Pada proses pembayaran dilakukan dengan dua cara yaitu pembayaran secara tunai di toko atau mengirim melalui ATM dan dilakukan oleh pelanggan dan reseller.

c. Proses Pengiriman Barang

Barang pesanan pelanggan atau reseller yang dikirim melalui jasa ekspedisi pengiriman dan biasanya bekerjasama dengan PT. POS Indonesia Kabupaten Bantul Yogyakarta, proses pengiriman barang dengan melihat tarif ongkos kirim kemudian menginformasikan kepada pelanggan atau reseller, penjual menyiapkan barang yang dipesan oleh pelanggan atau reseller kemudian mengemas barang yang akan dikirim serta menyertakan identitas seperti nama penerima dan pengirim, alamat penerima dan pengirim, nomor telepon penerima dan pengirim yang bisa dihubungi. Kemudian jasa ekspedisi akan membuatkan nomor resi untuk mengirim barang kepada pelanggan ataupun reseller. Selanjutnya jasa ekspedisi akan mengirim sesuai antrian pengiriman.

\section{Use Case Diagram Sistem Manual}

Use Case Diagram adalah rangkaian atau uraian sekelompok yang saling terkait dan membentuk sistem secara teratur yang dilakukan atau diawali oleh sebuah actor. Use case digunakan untuk membentuk tingkah laku benda dalam sebuah model serta direalisasikan oleh sebuah kolaborasi [10]
Gambar 1 adalah Use Case Diagram dari sistem manual KWT Ngudi Rejeki:

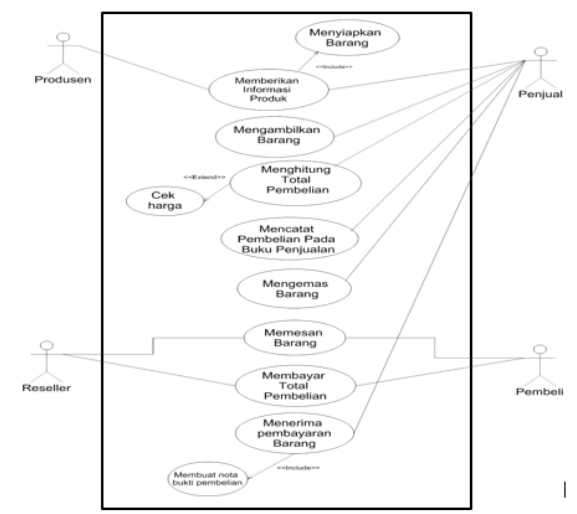

Gambar 2 Use Case Diagram Sistem Manual

Diagram Use Case sistem manual diatas menggambarkan prosedur system berjalan pada kegiatan transaksi penjualan dan pembelian produk pada KWT Ngudi Rejeki, dimana seluruh actor yang terlibat seperti produsen, penjual, reseller dan pembeli masih melakukan transaksi jual beli secara manual, mulai dari proses menyiapkan barang hingga membuatkan nota bukti pembelian seperti dijelaskan pada Use Case Diagram diatas.

Dari gambar Use Case tersebut diatas maka dapat dideskripsikan dalam tabel berikut:

Tabel 1. Deskripsi Use Case Memesan Barang

\begin{tabular}{|c|c|}
\hline Use Case Name & Memesan Barang \\
\hline Requirement & Reseller dan pelanggan Memesan Barang \\
\hline Goal & $\begin{array}{l}\text { Reseller dan pelanggan memesan barang dari } \\
\text { penjual }\end{array}$ \\
\hline Pre-Conditions & $\begin{array}{l}\text { Reseller dan pelanggan memperoleh informasi } \\
\text { produk dari penjual }\end{array}$ \\
\hline Post-Conditions & $\begin{array}{l}\text { Penjual melayani pemesanan dan pembelian } \\
\text { dari reseller dan pelanggan }\end{array}$ \\
\hline Failed end Conditions & Stok barang habis \\
\hline Actors & Reseller dan pelanggan \\
\hline \multirow[t]{2}{*}{ Main Flow/Basic Path } & $\begin{array}{l}\text { 1. Reseller dan pelanggan memperoleh } \\
\text { informasi produk dari penjual }\end{array}$ \\
\hline & $\begin{array}{l}\text { 2. Reseller dan pelanggan menghubungi } \\
\text { penjual untuk menanyakan informasi } \\
\text { produk lebih lengkap } \\
\text { 3. Reseller dan pelanggan memesan barang } \\
\text { kepada penjual } \\
\text { 4. Penjual mencatat pesanan dan menyiapkan } \\
\text { barang yang dipesan }\end{array}$ \\
\hline Alternate Flow/Invariant $A$ & $\begin{array}{l}\text { A1. Reseller dan pelanggan membuat daftar } \\
\text { pesanan barang yang akan dikirim }\end{array}$ \\
\hline Invariant $B$ & $\begin{array}{l}\text { B1. Reseller dan pelanggan memperoleh } \\
\text { informasi produk dari penjual } \\
\text { B2. Reseller dan pelanggan menghubungi } \\
\text { penjual untuk menanyakan informasi produk } \\
\text { lebih lengkap } \\
\text { B3. Reseller dan pelanggan memesan barang } \\
\text { kepada penjual } \\
\text { B4. Reseller dan pelanggan tidak dapat } \\
\text { memesan barang }\end{array}$ \\
\hline
\end{tabular}

Dan tabel diatas mendeskripsikan Use Case Diagram pada transaksi utama dalam use case tersebut yaitu proses memesan produk, sehingga dapat dijabarkan dalam tabel diatas. 


\section{e. Scenario kebutuhan Pengunjung Pengunjung dapat melihat daftar dan informasi produk, daftar menjadi pelanggan/pembeli atau reseller, melihat komentar dan testimoni}

\section{Kebutuhan Sistem}

Analisis kebutuhan sistem pada tahap perancangan sistem usulan EBAKUL berbasis website meliputi:

a. Skenario Kebutuhan Admin Admin dapat mengelola daftar dan informasi produk, upload informasi, gambar dan video produk, kelola data produsen, reseller, dan pelanggan, kelola pesanan kelola konfirmasi pembayaran, kelola pengiriman, melihat daftar dan informasi produk dan kelola komentar dan testimoni.

b. Skenario Kebutuhan Produsen

Produsen dapat kelola daftar dan informasi produk, upload informasi, gambar dan video produk, melihat daftar dan informasi produk, melihat data diri dan ubah data diri, ubah password

c. Skenario Kebutuhan Reseller

Reseller dapat melihat daftar dan informasi produk, melihat data diri dan ubah data diri, mengambil informasi produk dan download gambar dan video produk, memesan, pilih jasa ekspedisi, memperoleh informasi detail pembayaran dan pengiriman, konfirmasi pesanan dan cetak pesanan, dan konfirmasi pembayaran, berkomentar dan mengirim testimoni, ubah password.

d. Scenario kebutuhan pelanggan

Pelanggan atau pembeli dapat melihat produk, melihat data diri dan ubah data diri, memesan produk, pilih jasa ekspedisi, memperoleh informasi detail pembayaran dan pengiriman, konfirmasi pesanan dan cetak pesanan, dan konfirmasi pembayaran, berkomentar dan mengirim testimoni, ubah password. a. Pengguna sistem kecuali pengunjung harus melakukan login untuk dapat mengakses sistem E-BAKUL dan melakukan logout

b. Sistem melakukan penyimpanan data admin, data produsen, data reseller, data pelanggan, data produk beserta gambar dan videonya, daftar pesanan, data pembayaran dan pengiriman, dan data komentar serta testimoni.

c. Sistem melakukan identifikasi dan pencocokan antara username dan password pada saat pengguna melakukan login.

d. Sistem menampilkan informasi dan daftar produk, daftar produsen, reseller, daftar pelanggan, daftar pesanan, informasi detail pembayaran dan pengiriman produk.

e. Sistem melakukan kalkulasi stok produk

f. Sistem melakukan pencetakan bukti pesanan.

g. Sistem menyimpan konfirmasi pesanan dan pembayaran, komentar dan testimoni dari pengguna.

h. Sistem menampilkan status pesanan dan pembayaran.

i. Sistem melakukan penyimpanan password baru yang telah diubah oleh produsen, reseller, dan pelanggan. 


\section{Rancangan Use Case Diagram Usulan \\ Berdasarkan analisis kebutuhan} perancangan sistem E-BAKUL pada KWT Ngudi Rejeki khususnya dengan merek kelorida maka dapat digambarkan dengan diagram use case dengan model sea level:

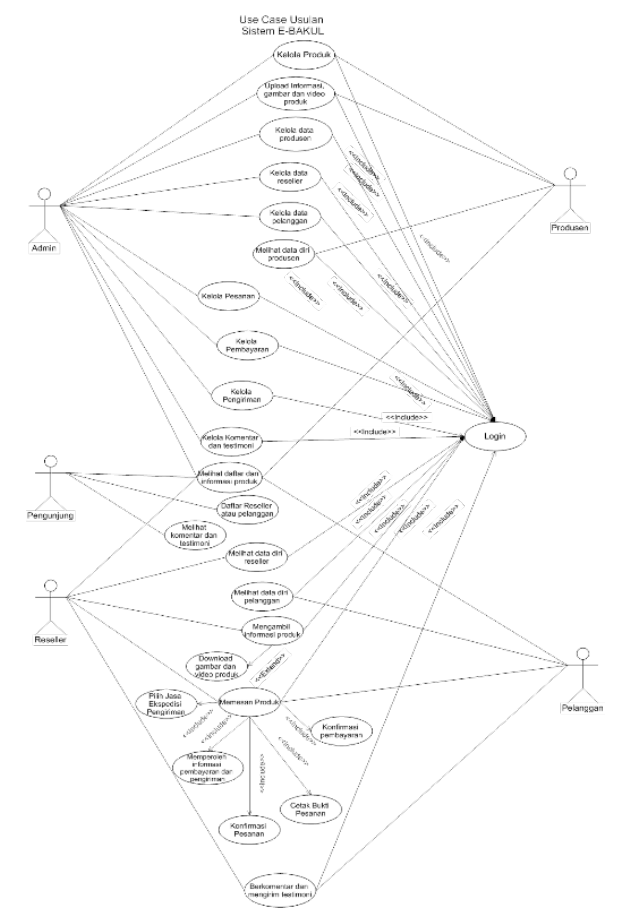

Gambar 3. Use Case Diagram Sistem Usulan

Use Case Diagram diatas menggambarkan sistem usulan yang akan diimplementasikan dalam bentuk website, dimana dalam use case usulan ini seluruh transaksi dilakukan secara online selain itu yang membedakan actor dalam use case ini terdiri dari lima actor antara lain Admin yang dapat mengelola seluruh aktivitas, produsen yang dalam hal ini sebagai penjual yang menyediakan produk, reseller sebagai penjual tangan kedua yang dapat memperoleh informasi produk secara lengkap tanpa harus menghubungi produsen setiap saat, pelanggan yang merupakan pembeli non reseller yang telah memiliki akun untuk mengakses website E-BAKUL, dan pengunjung yang hanya bisa melihat produk.
Dari gambar Use Case tersebut diatas maka dapat dideskripsikan dalam tabel berikut:

Tabel 2. Use Case Diagram Sistem Usulan

\begin{tabular}{|c|c|}
\hline Use Case Name & $\begin{array}{l}\text { Memesan Produk termasuk Konfirmasi Pesanan, } \\
\text { Memperoleh Informasi Pembayaran Dan } \\
\text { Pengiriman, Pilih Jasa Ekspedisi Pengiriman, } \\
\text { Cetak Bukti Peganan, dan Konfirmasi Pembayaran }\end{array}$ \\
\hline \begin{tabular}{|l} 
Requirement \\
\end{tabular} & $\begin{array}{l}\text { Reseller dan pelanggan dapat memesan produk } \\
\text { termasuk konfirmasi pesanan, memperoleh } \\
\text { informasi pembayaran dan pengiriman, pilih jasa } \\
\text { ekspedisi pengiriman, cetak bukti pesanan, dan } \\
\text { konfirmasi pembayaran }\end{array}$ \\
\hline \begin{tabular}{|l} 
Goal \\
\end{tabular} & $\begin{array}{l}\text { Reseller dan pelanggan dapat memesan produk } \\
\text { termasuk konfirmasi pesanan, memperoleh } \\
\text { informasi pembayaran dan pengiriman, pilih jasa } \\
\text { ekspedisi pengiriman, cetak bukti pesanan dan } \\
\text { konfirmasi pembayaran gecara online melalui web }\end{array}$ \\
\hline \begin{tabular}{|l|} 
Pre-Conditions \\
\end{tabular} & $\begin{array}{l}\text { Reseller dan pelanggan telah login ke menu } \\
\text { khusus untuk memesan produk }\end{array}$ \\
\hline \begin{tabular}{|l|} 
Post-Conditions \\
\end{tabular} & $\begin{array}{l}\text { Daftar katalog pemesanan produk, konfirmasi } \\
\text { pesanan, konfirmasi pembayaran dan bukti } \\
\text { pesanan bagi reseller dan pelanggan }\end{array}$ \\
\hline \begin{tabular}{|l} 
Failed and Conditions \\
\end{tabular} & $\begin{array}{l}\text { Reseller dan pelanggan batal memesan atau stok } \\
\text { produk habis }\end{array}$ \\
\hline \begin{tabular}{|l} 
Actors \\
\end{tabular} & Reseller dan pelanggan \\
\hline Main Flow/Basic Path & $\begin{array}{l}\text { 1. Reseller dan pelanggan login ke menu khusus } \\
\text { reseller dan pelanggan } \\
\text { 2. Sistem secara otomatis menampillkan menu } \\
\text { pemeganan produk } \\
\text { 3. Reseller dan pelanggan memasukkan produk } \\
\text { yang ingin dipesan } \\
\text { 4. Sistem akan menambahkan produk yang } \\
\text { dimasukkan kedalam daftar pesanan } \\
\text { 5. Reseller dan pelanggan pilih jasa ekspedisi } \\
\text { pengiriman } \\
\text { 6. Reseller dan pelanggan konfirmasi pesanan } \\
\text { 7. Sistem menampilkan informasi detail } \\
\text { pembayaran dan pengiriman } \\
\text { 8. Sistem menampillkan menu cetak bulkti } \\
\text { pesanan } \\
\text { 9. Reseller atau pelanggan melakukan } \\
\text { konfirmasi pembayaran }\end{array}$ \\
\hline Alternate Flow/Invariant $A$ & $\begin{array}{l}\text { A1. Sistem menampilkan menu khusus pesanan } \\
\text { produk bagi reseller dan pelanggan }\end{array}$ \\
\hline \multirow[t]{2}{*}{ Invariant $B$} & $\begin{array}{l}\text { B1. Reseller dan pelanggan login ke menu khusus } \\
\text { reseller dan pelanggan } \\
\text { B2. Reseller dan pelanggan mengigi form pesanan } \\
\text { produk }\end{array}$ \\
\hline & $\begin{array}{l}\text { B3. Sistem tidak dapat melayani pesanan produk } \\
\text { B4. Sistem secara otomatis menampilkan pesan } \\
\text { "Anda tidak dapat memesan produk saat ini, stok } \\
\text { produk habis" } \\
\text { "Bukti pesanan gagal dicetak" }\end{array}$ \\
\hline
\end{tabular}

Tabel diatas mendeskripsikan Use Case Diagram pada aktivitas utama dari system usulan yaitu proses transaksi pemesanan produk yang dapat dilakukan oleh Reseller dan Pelanggan biasa.

\section{Rancangan Diagram Aktivitas}

Activity Diagram digunakan untuk membantu memahami keseluruhan proses yang juga bermanfaat untuk menggambarkan interaksi antara beberapa use case. Diagram ini mirip dengan flowchart karena memodelkan workflow dari satu aktivitas ke aktivitas lainnya atau dari satu aktivitas ke status [10]. 
Sumber: [Priyadi:2014]

Gambar 3 merupakan Diagram Aktivitas pemesanan pada sistem E-BAKUL:

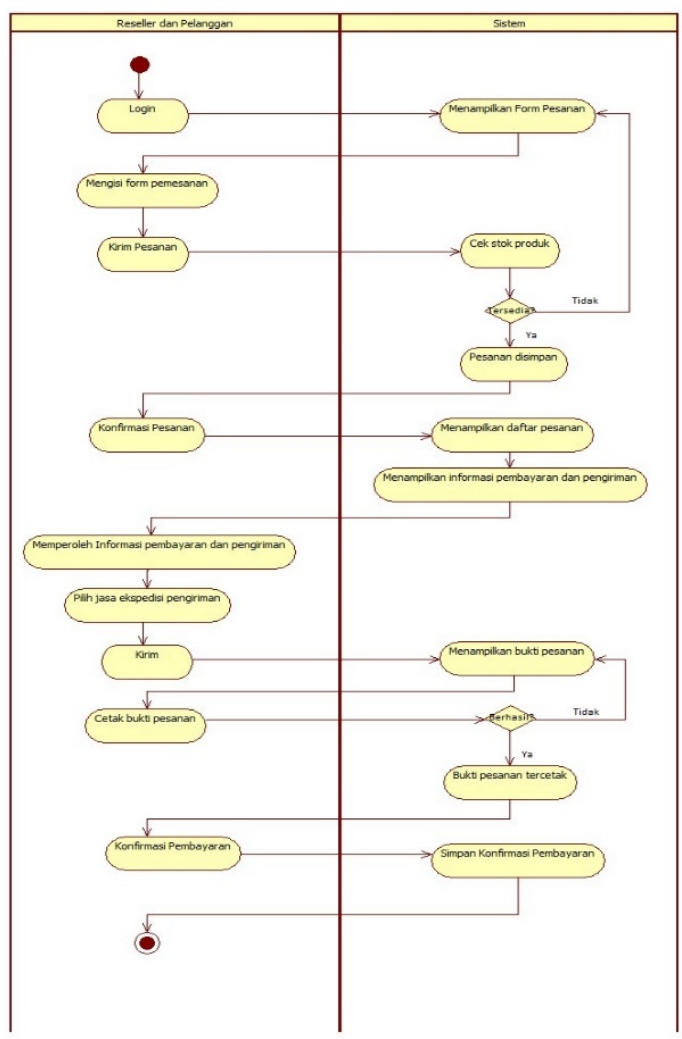

Gambar 4. Diagram Aktivitas Pemesanan

Diagram Aktivitas Pemesanan produk termasuk didalamnya meliuti aktivitas konfirmasi pemesanan, memperoleh informasi pembayaran dan pengiriman, pilih jasa ekspedisi, cetak bukti pesanan dan konfirmasi pembayaran yang dapat diakses oleh Reseller dan Pelanggan.

\section{Rancangan ERD}

ERD (Entity Relationship Diagram) adalah diagram yang digunakan untuk menggambarkan hubungan antara data store yang ada dalam diagram arus data [4].

Berikut ini notasi diagram E-R menurut Priyadi:

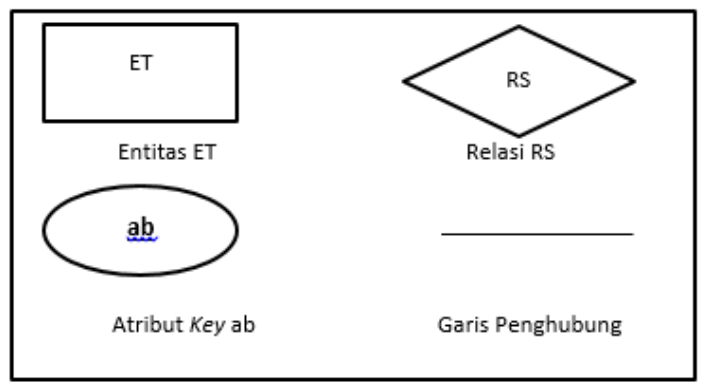

Gambar 5. Notasi Diagram E-R

Notasi dasar diagram E-R menurut Priyadi [11] antara lain:

1. Entitas merupakan notasi untuk mewakili suatu objek dengan karakteristik sama, yang dilengkapi oleh atribut, sehingga pada suatu lingkungan nyata akan berbeda dengan objek lainnya. pada umumnya, objek dapat berupa benda, pekerjaan, tempat, dan orang.

2. Relasi merupakan notasi yang digunakan untuk menghubungkan beberapa entitas berdasarkan fakta pada suatu lingkungan.

3. Atribut merupakan notasi yang menjelaskan karakteristik suatu entitas dan juga relasinya. Atribut dapat sebagai key yang bersifat unik, yaitu Primary Key atau Foreign Key. Selain itu, atribut juga dapat sebagai atribut deskriptif saja, yaitu sebagai pelengkap deskripsi suatu entitas dan relasi.

4. Garis Penghubung merupakan notasi untuk merangkai keterkaitan antara notasi-notasi yang digunakan dalam Diagram E-R, yaitu entitas, relasi, dan atribut.

Berikut ini merupakan ERD dari Rancangan sistem E-BAKUL

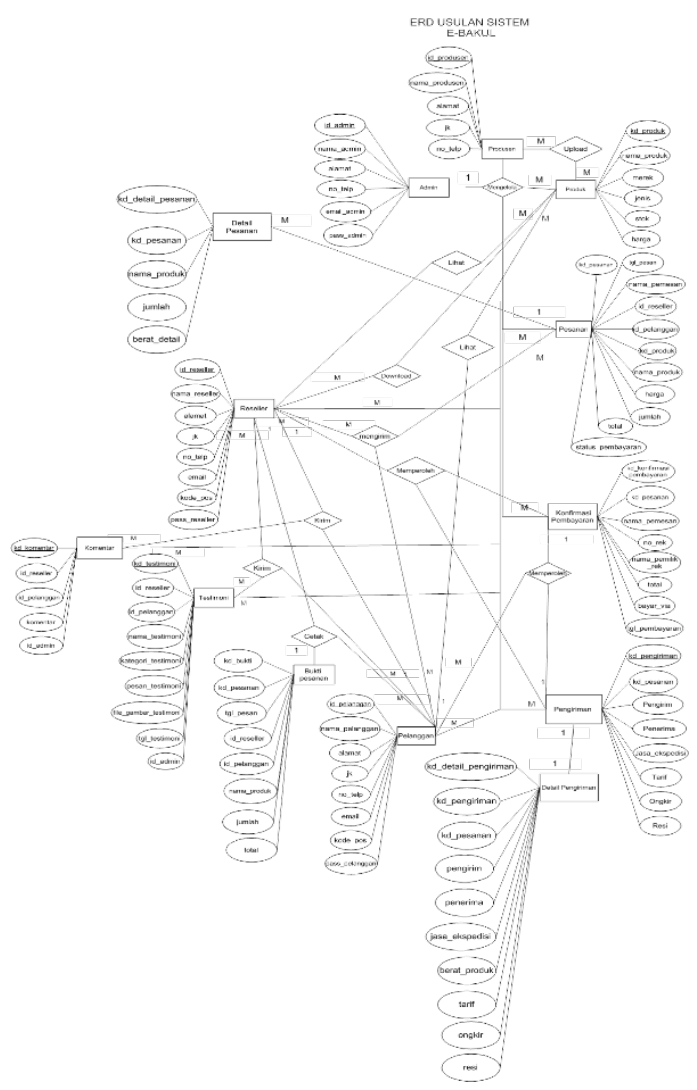

Gambar 6. ERD Sistem Usulan 
ERD sistem usulan ini menggambarkan rancangan sistem E-BAKUL pada KWT Ngudi Rejeki sesuai dengan entitas dan atribut pada database yang telah dirancang. Dimana entitas yang digunakan antara lain: Admin, produsen, produk, Reseller, Pelanggan, Pesanan, Detail Pesanan, Bukti pesanan, Konfirmasi Pembayaran, Pengiriman, Detail pengiriman, Komentar, dan Testimoni yang masing-masing memiliki atribut dengan id masing-masing sebagai primary key.

\section{Rancangan LRS}

LRS atau Logical Record Structure) berasal dari setiap entity yang diubah kedalam bentuk sebuah kotak dengan nama entity berada diluar kotak dan atribut berada diluar kotak [4]

Gambar 10 merupakan LRS dari rancangan sistem E-BAKUL:

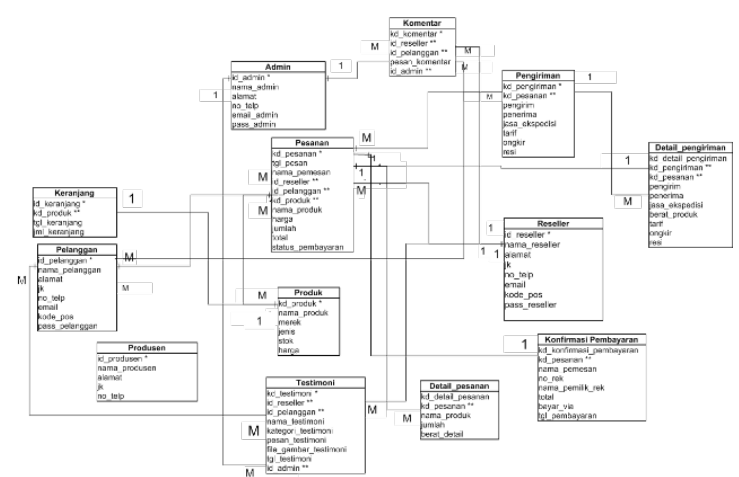

Gambar 7. LRS Sistem Usulan

LRS sistem usulan diatas menggambarkan representasi rancangan ERD, dimana entitas yang terdapat dalam rancangan LRS memiliki entitas yang sama dengan rancangan ERD.

\section{Rancangan Prototype}

Rancangan prototype ini berupa rancangan tampilan website E-BAKUL yang dapat digunakan oleh user.

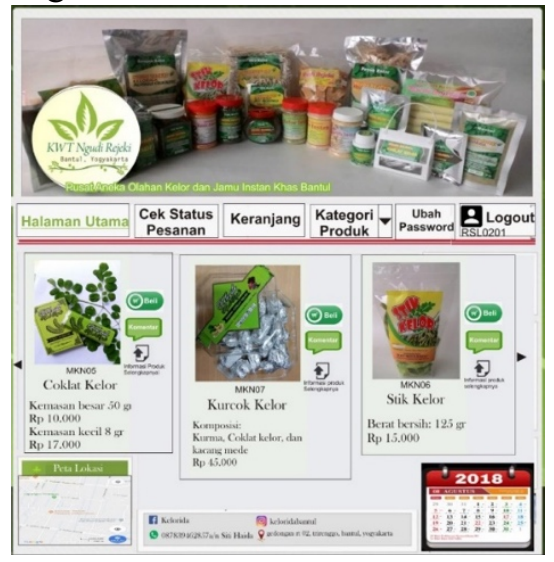

Gambar 8. Prototype Halaman Reseller

Prototype diatas merupakan desain halaman utama untuk Reseller setelah login dimana dalam halama utama ini reseller dapat melakukan pemesanan, cek status pesanan, ubah password, memperoleh informasi produk dan download gambar produk, serta dapat memberikan komentar dan testimoni.

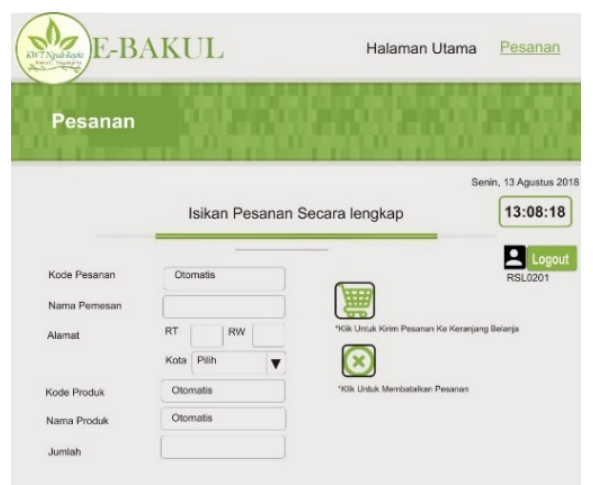

Gambar 9. Prototype Form Pemesanan Produk Pada Halaman Reseller

Sedangkan dalam prototype form pemesanan reseller dapat mengisi kelengkapan data saat akan melakukan pemesanan dengan mengisi nama, alamat dan jumlah sedangkan kode pesanan, kode produk akan otomatis terisi saat reseller klik tombol beli, selanjutnya untuk melanjutkan pemesanan klik tombol dengan icon keranjang.

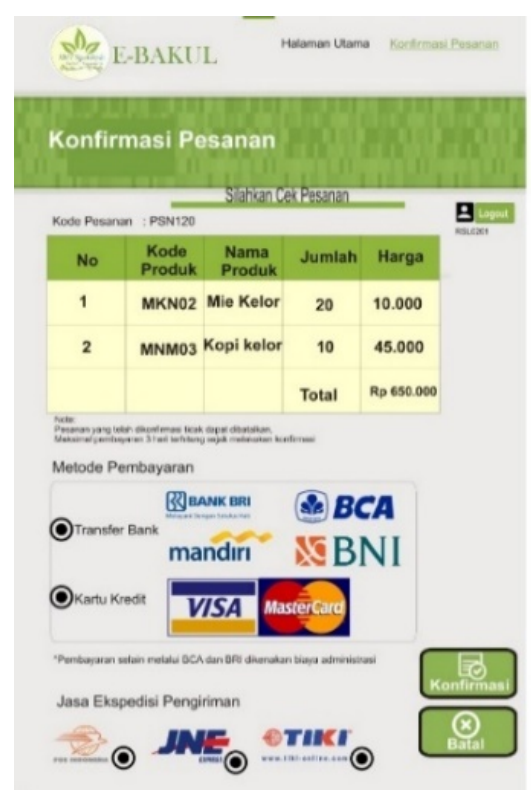

Gambar 10. Prototype Konfirmasi Pesanan

Dalam prototype form konfirmasi pesanan ini reseller diminta untuk mengkonfirmasi 
pesanan dengan melakukan cek produk yang dipesan, kemudian memilih metode pembayaran dan jasa ekspedisi dan klik konfirmasi untuk melanjutkan ke pembayaran.

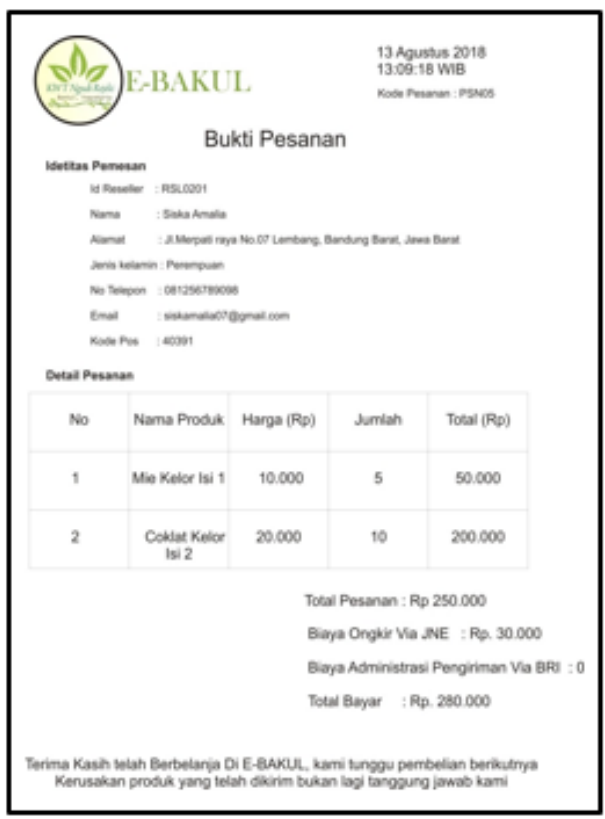

Gambar 11. Prototype Bukti Pesanan

Setelah reseller klik konfirmasi maka akan muncul bukti pesanan, didalam bukti tersebut akan tampil identitas pemesan dan detail pesanan serta jumlah pesanan yang harus dibayar.

Sistem informasi E-BAKUL (E-Babak Kuliner Bantul) ini dirancang unutk memudahkan user dalam hal ini produsen, reseller, dan pembeli untuk melakukan transaksi jual beli produk olahan kelor hingga menmperoleh output berupa bukti pesanan. Sistem ini dirancang untuk meminimalisir kesalahan perhitungan dalam proses transaksi juga memudahkan interaksi produsen dengan reseller maupun pembeli biasa.

\section{Jadwal Implementasi}

Jadwal implementasi merupakan jadwal perancangan sistem informasi E-BAKUL, dimulai dari persiapan awal hingga pembuatan laporan rancangan sistem.

Berikut ini tabel jadwal implementasi perancangan sistem E-BAKUL:
Tabel 3. Jadwal Implementasi

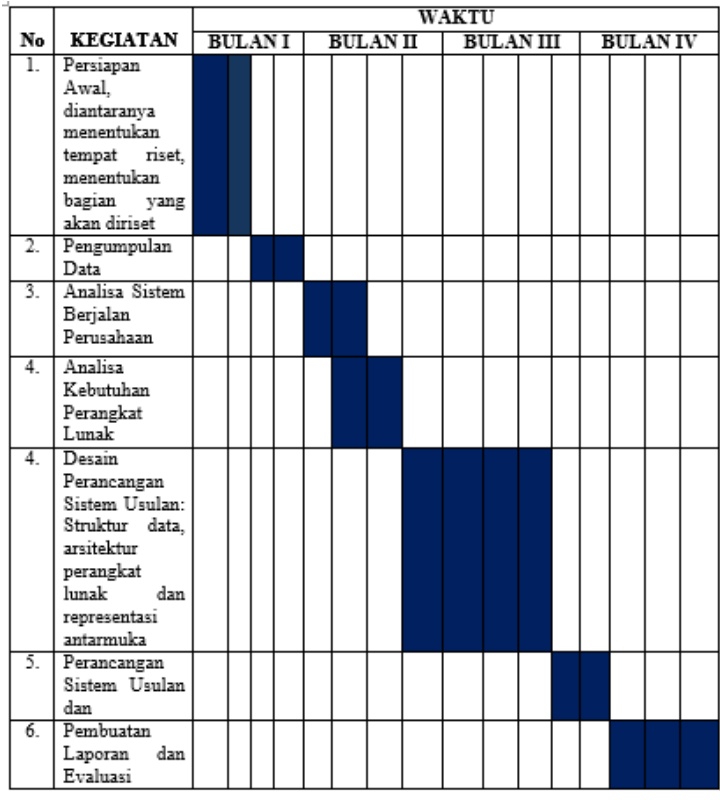

\section{SIMPULAN DAN SARAN}

\section{A. Kesimpulan}

Dengan adanya perancangan sistem EBAKUL atau singkatan dari E-Babakan Kuliner Bantul berbasis website yang telah diusulkan oleh penulis, maka diharapkan mampu:

1. Memberikan solusi dari permasalahan yang dialami KWT Ngudi Rejeki sebagai media pemasaran yang efektif dan efisien untuk menjangkau pasar lebih luas

2. Sebagai media penjualan untuk mengurangi resiko kesalahan perhitungan pada saat melakukan transaksi penjualan.

3. Menjembatani proses transaksi antara penjual dan pembeli tanpa harus datang langsung ke toko, menghemat waktu, tenaga dan biaya promosi serta pembelian nota.

4. Sebagai media berbagi informasi produk secara lengkap dan up to date antara penjual dan reseller

\section{B. Saran}

Agar sistem E-BAKUL yang telah diusulkan oleh penulis dapat berjalan sesuai dengan rencana yang telah dibuat, maka penulis memberikan saran untuk pihak KWT Ngudi Rejeki sebagai berikut:

1. Setiap pengguna sistem E-BAKUL mengetahui alur program yang diusulkan, sehingga program dapat berjalan dengan 
baik dan dapat ditanggulangi sejak dini sebelum terjadi kerusakan.

2. Sistem dapat diimplementasikan dengan baik, jika didukung dengan peralatan pendukung yang memadai, meliputi perangkat keras, perangkat lunak, dan sumber daya manusia yang mengoperasikan program tersebut.

3. Mengingat pentingnya data-data yang disimpan, maka penulis menyarankan untuk membuat back up atau cadangan file secara berkala untuk mengantisipasi apabila terjadi kerusakan atau kehilangan file.

4. Setiap sistem E-BAKUL dan peralatan pendukungnya yang digunakan harus dilakukan pemeliharan, pengecekan atau update jika diperlukan setiap bulan sekali agar sistem selalu dalam keadaan baik.

\section{DAFTAR PUSTAKA}

[1] M. P. R. Indonesia, "Rencana Strategi Kementerian Pertanian." http://www.pertanian.go.id/file/RENST RA_2015-2019.

[2] I. Mulyaningsih, "Wisata Budaya dan Kuliner Sebagai Strategi Belajar Darmasiswa di Cirebon,” 2017. http://repository.syekhnurjati.ac.id/726/

[3] S. dan T. Wahyudi, E-Commerce Untuk Indonesia Lebih Baik. Yogyakarta: Deepublish, 2017.

[4] A. A. Permana, "Rancangan Sistem Informasi Simpan Pinjam Pada Koperasi Guru Dan Pegawai Smp Negeri 45 Jakarta," JIKA (Jurnal Inform., vol. 1, no. 2, pp. 51-58, 2017, doi: $10.31000 /$ jika.v1i2.1400.

[5] R. S. Sidik, Wanda Putri, "Implementasi Model Waterfall Pada Sistem Informasi Pengiriman Barang Berbasis Web," J. Tek. Komput., vol. 5, no. 2, pp. 271-276, 2019, doi: 10.31294/jtk.v5i2.5126.

[6] M. U. Riki Harianto, Regiolina Hayami, "Rancang Bangun Aplikasi Katalog Online Dan Sistem Pemesanan Produk," J. Fasilkom, vol. 9, no. 2, pp. 440-447, 2019, doi: 10.37859/jf.v9i2.1419.

[7] M. Rosa AS and Shalahuddin, Rekayasa Perangkat Lunak Terstruktur dan Berbasis Objek. Bandung:
Informatika, 2015

[8] R. Rachman Andi, Beny, and E. Fernando, "Perancangan E-Commerce Berbasis Website Pada Toko Mirabella Batik Jambi," J. Ilm. Process., vol. 12, no. 2, pp. 1102-1117, 2017, [Online]. Available:

https://scholar.google.com/scholar?hl=i $\mathrm{d} \&$ as_sdt $=0 \% 2 \mathrm{C} 5 \& \mathrm{q}=$ Perancangan $+\mathrm{E}-$ Commerce + Berbasis + Website + Pada $+\mathrm{T}$ oko+Mirabella+Batik+Jambi+Andi\&bt $\mathrm{nG}=$.

[9] M. S. Mustaqbal, R. F. Firdaus, and H. Rahmadi, "PENGUJIAN APLIKASI MENGGUNAKAN BLACK BOX TESTING BOUNDARY VALUE ANALYSIS (Studi Kasus: Aplikasi Prediksi Kelulusan SNMPTN)," vol. I, no. 3, pp. 31-36, 2015.

[10] H. Tohari, Analisis Serta Perancangan Sistem Informasi Melalui Pendekatan UML. Yogyakarta: Andi Offset, 2014.

[11] M. . Yudi Priyadi, Kolaborasi SQL \& ERD dalam Implementasi Database. Yogyakarta: Andi Offset, 2014. 